\title{
Effectiveness of Automatic CAM Programming Using Machining Templates for the Manufacture of Special Production Tooling
}

\author{
Maciej Kowalski1,2 - Przemysław Zawadzki1, ${ }^{*}$ - Adam Hamrol ${ }^{1}$ \\ ${ }^{1}$ Poznan University of Technology, Faculty of Mechanical Engineering, Poland \\ 2 MK-Tech Company, Poland
}

The paper presents the methodology and implementation of original Automatic CAM programming using machining templates (ACPUT) dedicated to manufacturing special technological tooling. The development of ACPUT was inspired by the observation that although modern computer-aided design (CAD) / computer-aided manufacturing (CAM) systems can automatically create CAM programs, their universality makes them both difficult to use and inefficient because the programs created this way often contain errors. The presented programming procedure includes the development of specific machining templates based on technological knowledge gathered in a specially prepared database. These templates are dedicated to a group of parts characterized by the similarity of their geometric features. ACPUT makes it possible to reduce(in comparison to traditional CAM programming) the time required to develop a machining program, thereby positively impacting the total cost of tooling production. The paper aims to present results of testing the effectiveness of the use of ACPUT by technicians with different levels of experience (expert and beginner). The tests were carried out on special tooling - assembly equipment for plastic pipes, and compared program preparation time, machining time, and production costs.

Keywords: generative CAM process, CNC programming, technology design automation, knowledge-based engineering

Highlights

- Automatic CAM programming using machining templates (ACPUT) is dedicated to the manufacture of special technological tooling that consists of technologically similar parts.

- $\quad$ ACPUT makes it possible to shorten the time needed to develop a machining program and to reduce the total cost of tooling production.

- The effectiveness of the ACPUT procedure depends on the experience of programmers preparing the machining templates.

\section{INTRODUCTION}

Nowadays, manufacturing companies must respond quickly to diverse and dynamically changing market needs and expectations. This situation is related to, among other factors, the increasingly common personalization of products, which requires rapid responses to changes in demand in terms of volume and assortment while maintaining high product quality and highly efficient production processes [1] to [3].

To meet the expectations of the mass personalization of products, it is necessary to develop systems that allow for the extensive use of various data contained in product designs and their production technologies [4] to [6]. Such systems, including functions ensuring efficient data exchange between departments involved in production preparation, have been a standard in mass personalization-oriented companies for many years [7] and [8]. In addition, designers and technicians can use tools that make it possible to use the knowledge gained in previously implemented projects (i.e., knowledge-based engineering (KBE)) [9] and [10]. Examples of this are found in the automotive sector, household appliances, sanitary and electronic products, and other industry sectors where similar components with the same purpose may differ due to different vehicle variants.

One of the stages to prepare for product manufacture is the design and implementation of special technological tooling, which complements the standard equipment of production machines and equipment and is essential for manufacturing products whose design specifics need to be considered. Due to their intended use, universal (general purpose) and special (dedicated to specific machines, processes, and products) equipment can be distinguished [10] to [12].

The production of special technological tooling is an example of custom-made production, asmaketo-order (MTO) and engineering to order (ETO), in which the design of the device is based on the product model provided by the customer.

The process of production special technological tooling is carried out in stages and includes (Fig. 1):

1. Analysis of the three-dimensional (3D) CAD model of the product provided by the customer.

2. Development of a tooling model in the 3D CAD program adapted to the product's shape.

3. Export of designed 3D CAD models of tooling to the CAM program. 
4. Development of machining programs in CAM for individual parts of the tooling.

5. Manufacture of tooling parts on a computer numerical control (CNC) machine.

6. Tooling assembly and delivery to the customer.

This process is time-consuming and quite often inefficient (in the case of manufacturing groups of products) because despite containing similar manufacturing actions, it must be carried out for each unique product model separately [13].

Using previously acquired engineering knowledge, advanced parametric design methods in CAD systems make it possible to create special models, known as "generative models" in the literature. Such models enable the automation of the operations in Stages 1 and 2 (Fig. 1) related to the development of the tooling design.

Based on this approach in a small Polish company (MK-Tech Company), designing and producing special equipment for advanced technical companies from the automotive industry, a procedure for creating machining templates in the CAM system - Automatic CAM Programming Using Machining Templates (ACPUT) [14] was developed, which, in conjunction with a machining knowledge base, makes it possibleto automate the operations in stage 4 (Fig. 1). Since the ACPUT method is limited to a specified product group, the rules it creates are effective and efficient. The templates can be developed using any integrated $\mathrm{CAD} / \mathrm{CAM}$ class software that allows the parametric construction of CAD models and programming in a scripting language (e.g., Visual Basic for applications (VBA).Sincemachine programming in CAM systems is a time-consuming and high-cost process (it requires the involvement of highly qualified engineering staff), the aimof the ACPUT was to reduce time and minimize human participation in the programming of $\mathrm{CNC}$ machines (in the manufactureof special production equipment).
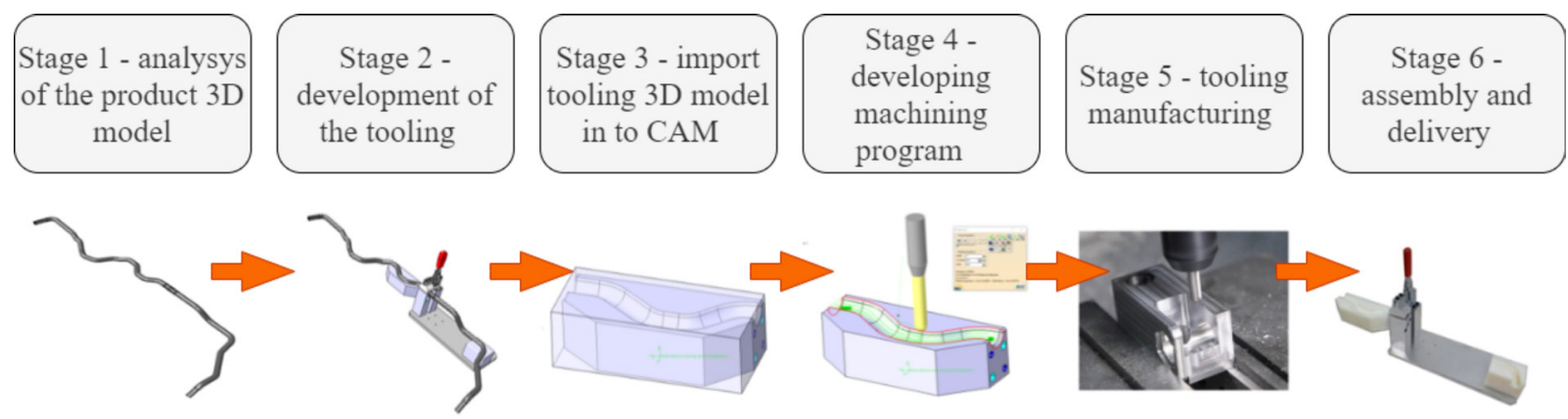

Generally, regardless of the type of CAM software used, programming in CAM systems can be divided into tasks relating to:

1. the definition of the workpiece shape,

2. the determination of subsequent machining operations,

3. the simulation and verification of the machining program.

In the beginning, the general geometric features are defined (i.e., the shape of the workpiece and the shape of the blank from which the part will be made). The user also defines his coordinate system with the zero position so that it is possible to orient the workpiece in the working space of the $\mathrm{CNC}$ machine.

The programming process involves determining the course of the machining process, depending on the complexity of the workpiece and its size. In individual machining operations, the technological engineer determines:

- the specific geometric elements of the CAD model for processing (planes, edges, points),

- the machining tool type and features,

- the machining strategy determining the machining tool path,

Fig. 1. Example of special production tooling manufacture according to ETO [14] 
- the technological parameters of the operation (speeds and the input/output paths of the machining tool relative to the workpiece).

All the settings must undergo initial verification and evaluation in the CAM program (in order to detect possible errors at the operational level). Then, the tool path for the specific operation is generated and saved in the part's program structure. This process is repeated separately for each operation, andthe geometric changes resulting from previously generated operations are considered. Finally, the whole process is simulated, and if the program requires corrections, the necessary changes are made in the selected operations. After verification, using a special translator, the so-called postprocessor creates a numerical control (NC) code that will be implemented on a specific machine tool.

The level of effectiveness of programming CAM depends on the opportunity to develop dedicated solutions to support and automation presented above sequence of activities. Most often, it is carried out using specific tools of the given CAM program (most recent systems offersuch functions). The most popular functions are based on recognizing the characteristic features of a CAD model FR and assigning appropriate machining cycles to them [17]. In practice, these tools can accelerate the work on program preparation but are only effective for models with relatively simple shapes. In the case of advanced surface models (such as the forms with shaping cavities described in this article), the proportion of automatic recognition of geometric features decreases, and the "manual" work of the technician increases to a large extent. These tools are, therefore, a hybrid solution that works well in a single case. Therefore, for a group of families of similar products (several to several dozen items), their use does not significantly affect the effectiveness of the CAM programming process.

Although the FR technology has been known for three decades, it remains the subject of various works [18]. The authors focus on the development of various algorithms that can more accurately analyse 3D models and more effectively indicate possible technological operations [19] and [20]. In turn, Zhou et al. [21] presented the FR method (supported by deep learning) for the selection of cutting tools, increasing the effectiveness and efficiency of this task. Another example is the use of FR for spot welding recognition. It should be noted that these works do not deal with the issue of the automation of CAM programming in a general perspective, which can actually improve the efficiency of this process, but only develops algorithms for searching for specific geometric features of 3D models.

Moreover, analysing the literature relating to the programming of $\mathrm{CNC}$ machines, it can be seen that not much attention has beenpaid to methods forautomating of CAM programming process. Most recent research mainly concerns the improvement of the manufacturing process itself.An example would be the study by Andrankaja et al. [22], in which the decision support method in $\mathrm{CAD} / \mathrm{CAM}$ design is described based on analysis of the data recorded in the NC code. In the opinion of Zhou and Wu [23], an important problem is the exchange of data between different CAD and CAM systems. They focused their attention on developing a method supporting a data exchange between various CAD/CAM systems, based on the "stl" universal data format. This means that their studyconcerns the third stage of programming related to data export within the process.

De Lacalle et al. [24] and [25] have presented methods for improving the CAM generation process in the production of special tooling (forging dies and injection moulds) according to high-speed milling (HSM) requirements. The main objective was to achieve a good surface quality directly from machining, without any additional, tedious, manual work. The authors have achieved the goal using a special postprocessor coded in $\mathrm{C}$ language. Once the CAM user had to define (on the CAD model) the theoretical boundaries of the tempered areas, the insert blocks, or the deposition material areas, the CNC program was changed automatically.

According to Zahid et al. [26], the effectiveness of NC program preparation is largely dependent on the experience of the user who manually prepares the machining plan. This author developed a special tool for recording, analysing, and improving the code during programming. As a result, both the planning time for machining and its complexity were reduced. Similar studies were presented by Deja and Siemiatkowski [27].

In turn, Tan and Ismail [28] described the methodology for recognizing the features of the CAD model, based on which appropriate operations in the CAM program are selected. Similar considerations were described in papers [29] to [31], presenting different approaches to the data exchange between the CAD and CAM programs, as well as to the recognition of the features of the objects processed, using the universal STEP files format.

In all the studies cited above, the $\mathrm{CNC}$ machine programming process had a low level of automation. The methods presented wereusually testedon 
simple examples, which makes it difficult to assess their usefulness in practice in industry, where the manufactured parts very often have complicated shapes, and the machining process must not only include shaping, but also surface treatment.

The automation of $\mathrm{CNC}$ machine programming is discussed in the study by Xu et al. [32]. They presented a method forautomatically generating machining tool paths, based on the data in the integrated CAD/CAPP/ CAM system. Recording the technological knowledge in the CAPP system and its further implementation in the CAM system was undertaken by Wang et al. [33]. In their study, Li et al. [34] developed a method that allows the shortening of machining planning time, demonstrating the relationship between machining data and the models used in the manufacturing process. Ma et al. [35] presented a similar approach in their study. In some studies, methods based on artificial intelligence were discussed [36] and [37], although automation in these cases concerned rather the tasks relating to the process of machining planning, and not merely program generation.

Kumar [38] presented an original system in which the automation of $\mathrm{CNC}$ code generation eliminated the need for specialist human knowledge and minimized the time required tocreate the program. Appropriate recording of technological knowledge wasimportant here, not only because of the quality of the tooling produced but also the quality of the $\mathrm{CNC}$ machine programming process in the CAM program. Li [39] provided an overview of the methods used in the recording of the technological knowledge used to prepare the machining process. Although he emphasized the importance of knowledge and the need to write it into the work, he did not specify a universal solution. It can be concluded that the selection of a tool for recording technological knowledge should be adapted to the case in question. More examples on this subject can also be found in [19] and [40] to [44].

In the literature of the subject, no reports confirm the effectiveness of the implementation of automation of CAM programming process in the case of manufacturing a group of products. Therefore, it can be assumed that systems dealing with such cases are not implemented at all or are prepared on an ad hoc basis. The ACPUT methodology fills this gap.

\section{PROGRAMMING CAM WITH THE USE OF ACPUT}

The basis of ACPUT [12] is the development of a special machining template that represents all the technological operations possible for a given group of products. Data and information needed to prepare such a template are stored in the special knowledge base. Knowledge acquired mainly from specialists in a given field is accumulated and written formally, so as to be understood by the computer program. To ensure the correct operation of the machining template, and thus the automation of the preparation process in the CAM environment, 3D models for the tooling must be properly described in the CAD program (i.e., categorization of features and their assignationto the model). Based on this description, the template later automatically selects the appropriate features for the given part.

ACPUT is presented in the form of a procedure and includes the following steps (Fig. 2):

1. Analysis of 3D CAD models of a given group of tooling parts.

2. Preparation of the technological knowledge base.

3. Defining the geometry necessary to build the machining template and publishing it.

4. Preparation of machining template.

5. Preparation of machining program for each part of the given group of tooling parts (with simulation in CAM program).

6. Preparation of NC program.

Step 1 is an analysis of all the CAD models of tooling (i.e., variants) included in a given group, which means checking the technological design of the individual parts and determining the types of machining operations required. The geometric similarities of the parts should be identified, and any variants determined. Once the objects have been analysed, the next step is a description of the technological process in the form of a knowledge base.

In Step 2, the knowledge base is built by breaking the technological knowledge down into basic units (i.e., detailed data), divided into two categories. The metadata of databaseis presented in Table 1.

Step 3 introduces modifications into the structure of the CAD models, adding a special description for those geometric elements associated with specific machining operations. It can be considered that such a description is a kind of record of metadata in the CAD model, after which geometric elements can be identified and specific actions performed in them in the CAM program (e.g., automatic connection of selected geometric elements of a given model (surface, line, and point) with a specific machining operation, saved onthe machining template). The advantage of this approach is that regardless of the geometric differences of the described elements in different variants of the parts, they will always be interpreted 


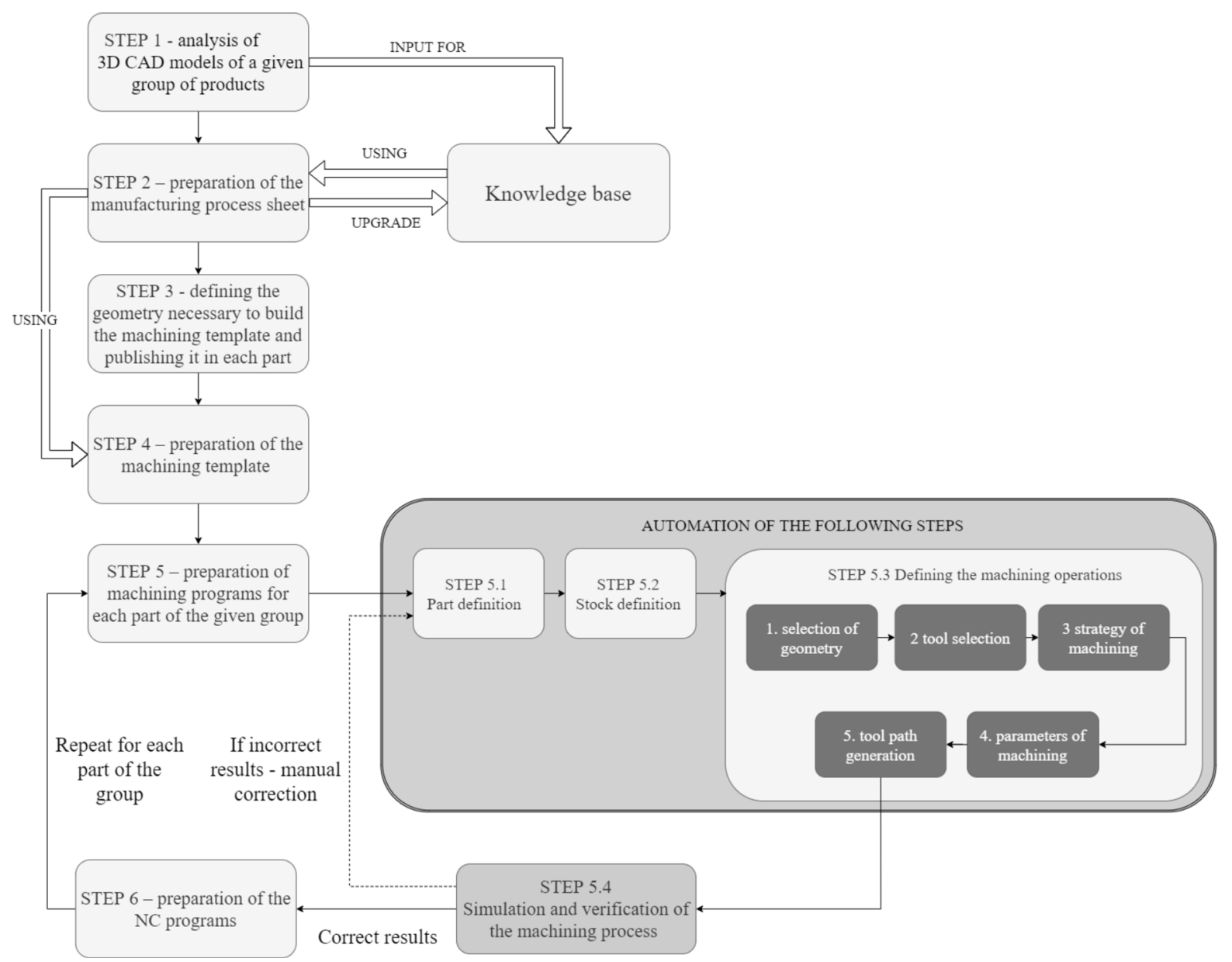

Fig. 2. ACPUT procedure

Table 1. Metadata of manufacturing database

\begin{tabular}{|c|c|}
\hline \multicolumn{2}{|l|}{ Knowledge Database } \\
\hline Basic data (general for whole process) & Machining operations (gathering for each operation separately) \\
\hline I. Definition of machine tool & I. Selection of type of machining operation \\
\hline a) Number of controlled axes & II. Choice of machining strategy \\
\hline b) Workspace & a) The way the tool moves \\
\hline c) Shifts along individual axes & b) Milling direction \\
\hline d) Type of control & III. Choice of geometry \\
\hline II. Definition of the workpiece & IV. Selection of machining tool \\
\hline a) Workpiece geometry & a) Tool Type \\
\hline III. Definition of the stock & b) Type of frame \\
\hline a) Stock geometry & c) Dimensions \\
\hline b) Position of the stock relative to the workpiece & V. Determination of cutting parameters \\
\hline IV. Definition of workpiece position in the machine tool & a) Depth of cut \\
\hline a) Position of workpiece coordinate system & b) Cutting width \\
\hline b) Orientation of workpiece coordinate system (X axis, $Z$ axis) & c) Cutting speed \\
\hline V. Definition of how to mount the blank in the machine tool & d) Feed speed \\
\hline a) Fastening geometry & VI. Tool path generation \\
\hline \multicolumn{2}{|l|}{ VI. Definition of the safe plane } \\
\hline a) Location of the safe plane & \\
\hline
\end{tabular}


in the same way. This is one of the conditions for the correct operation of ACPUT.

The next step (Step 4) consists of the use of the data contained in the knowledge base and, specifically, described CAD models to create a machining template in the CAM program for a given type of part. Data entered into the knowledge base, including all the basic data such as machine and workpiece data, as well as describing all possible operations to be performed, along with a definition of the machining parameters, tools, etc., are then added to the CAM template. The CAM template automates the generation of a machining program (Step 5 and Step 6) and only requires the selection of the machined part. The appropriate algorithm in CAM then adapts the machining process to it.

The automatically generated process should be simulated, assessing the compliance of the results with the assumptions for the given process. In case of any discrepancies, the knowledge record in the database should be improved. The end of the procedure is the preparation of programs specifically for the selected CNC machine.

Executing the ACPUT procedure requires different skills in manufacturing knowledge and $\mathrm{CAD} / \mathrm{CAM}$ systems operation. It is therefore assumed that Step 1 and 2 are realized by an experienced technical. Step 3 can be carried out by even a novice CAM programmer; however, Step4 requires skills at the expert CAM programmer level. The last two steps can be also realized by novice CAM programmers.

\section{ACPUT EFFECTIVENESS TEST}

\subsection{Research Methodology}

Preliminary tests of ACPUT [8] showed that proceeding according to the ACPUT procedure leads to achieving an effective machining program, meaning that it is compliant with the requirements, according to the manufacturing sheet (ACPUT methodology does not concern optimizing manufacturing program).

However, the question arises whether ACPUT is equally efficient if used in everyday industrial practice. To answer this question, a comparative study of the programming efficiency of machining selected group of production tools by operators with various experience (using any tools) was conducted.

For comparison of ACPUT efficiency to the traditional way of programming a test was performed. The test was carried out with 10 CAM programmers, five of whom were experts with several years of experience and five were beginners with several months of experience. The following programming outcomes were compared in the analysis:

1. the time needed to prepare the machining programs for individual tooling part $T_{i}$ [min],

2. cumulative machining time for preparing all tooling groups $T_{c}$ [min],

3. sum of the cost of programming and the cost of machiningof eachtool $C_{m}$ [EUR].

Additionally, the tests were madeas to whether the parts machined in accordance with the prepared programs meet the quality requirements (geometric accuracy and surface roughness).

The following activities were considered by measuring the programming time $\left[T_{i}\right]$ :

- for the first part - becoming acquainted with the whole family of products; detailed familiarization with the first part of the family; becoming acquainted with the manufacturing processsheet for the first part of the family, direct time to prepare the program for the first part in the CAM program (experts and beginners)/preparation time for the machining template (ACPUT procedure),

- for each subsequent part of the family - becoming acquainted with the $n^{\text {th }}$ part of the family, getting to know the manufacturing process sheet for the $n^{\text {th }}$ part of the family; direct program preparation time for the $n^{\text {th }}$ part of the family in the CAM program (experts and beginner)/starting the machining template for the $n^{\text {th }}$ part (ACPUT procedure).

Tooling for plastic pipes assembly, consisting of 50 parts (Fig. 3 - presents only part of them)and manufactured by milling on a CNC machine, was selected for testing. Acting in accordance with the assumptions of ETO (the tooling model was provided by the customer), it was assumed that when preparing programs, it was not possible to interfere with the geometry of the 3D models of the tools, and the files were saved in the universal STEP file format.

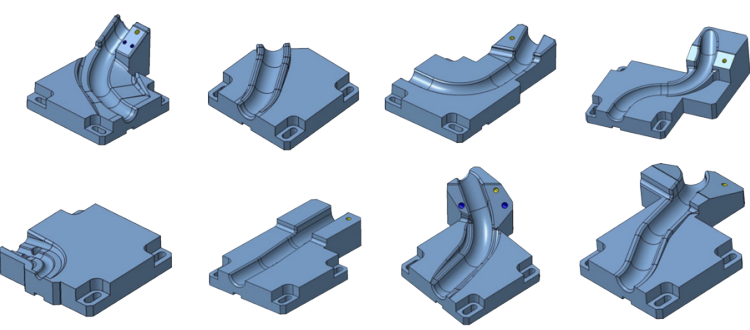

Fig. 3. Part of the group of special tooling - assembly equipment for plastic pipes

In accordance with the ACPUT procedure, the different geometric elements of each tool in the group 
were first recognized (e.g., Fig. 4), and then described by machining operations, for which the detailed course of the machining process was recorded in the knowledge base. Based on that, the manufacturing process sheets were prepared, consisting of detailed data about machining for each part. All those initial steps (Steps 1 and 2) were made by a specialist (technician).

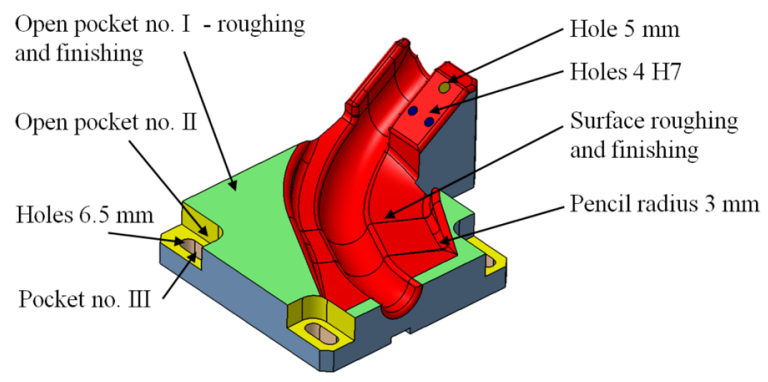

Fig. 4. Recognized geometric elements of single tool

The next step consisted in modification of the 3D models for each part, and the addition of a special description of those geometric elements associated with specific machining operations. These are so- called publications in CATIA V5. Publications are a description enabling the program to refer to the objects they concern. They can be considered a kind of metadata (or tags), after which geometric elements can be identified and other actions performed on them. In the case described, the publications made it possible, for example, to make a later automatic connection of selected geometric elements of a given model (surface, line, and point) with a specific machining operation, saved in the machining template. The advantage of this approach is that, regardless of the geometric differences of the published elements in different variants of the parts, they will always be interpreted in the same way in the program. This is necessary to ensure the correct operation of the automated method described. The list of publications is added to the structure of the given CAD model.

Having properly described the $3 \mathrm{D}$ models and the knowledge base for the machining process, a CAM process template was prepared in the CATIA V5 program. Data stored in the knowledge base was rewritten to the template, including basic machine and workpiece data, and those describing all the possible operations to be carried out along with a definition of

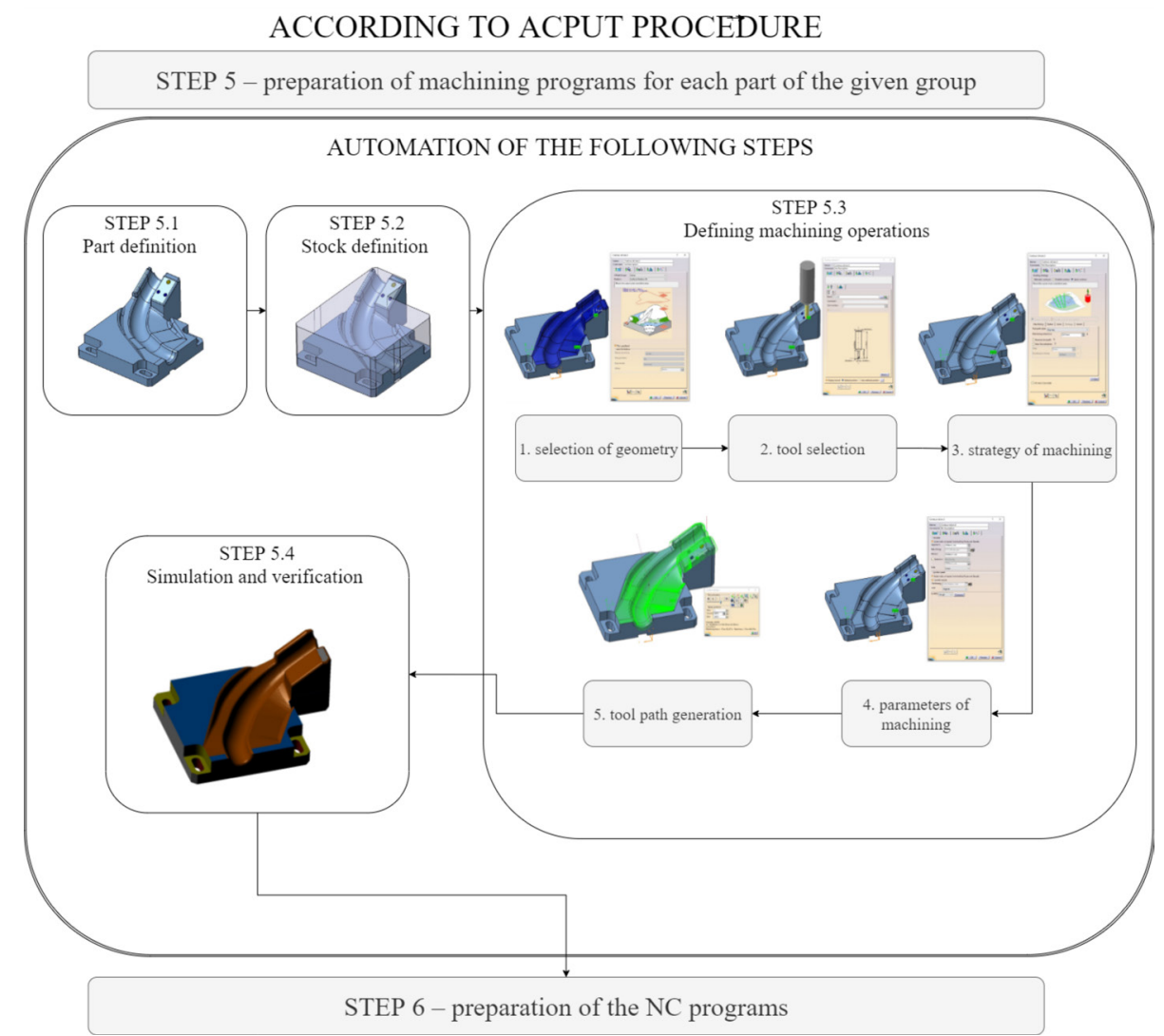

Fig. 5. Process of programming CNC machine with automatic solution using ACPUT procedure 
the machining parameters, tools, etc. The use of the template makes it possible to automate the generation of the machining program, requiring only an indication of the workpiece variant. The appropriate algorithm in the CAM program then adapts the machining process to it. All the stages in the development of the machining program usingthe automatic method areshown in Fig. 5.

\subsection{Results and Discussion}

Machining programs were developed for each of the 50 parts according to:

a. the ACPUT procedure

b. the standard procedure:

- by beginner CAM programmers,

- by expert CAM programmers.

The manufacturing process sheets, developed by a technician in Step 2 of ACPUT, were also made available to the programmers (beginners and experts) so that the data forthe machining process were the same in all cases. In order to verify the surface quality and the accuracy of execution, one variant of the part was created according to the automatic program (ACPUT method) along with programs developed traditionally by an expert and a novice programmer. The machining quality obtained in all three cases was similar (the differences did not exceed the demands and tolerances assumed in the technological card). This is because in each case, it was based on a common data source: a knowledge base describing how a given part should be made. The differences between the programs (ACPUT procedure/expert programmers/ beginner programmers) mainly concerned the use of various functions of the CAM program to perform specific operations and the settings of the individual treatments, which in the analysed case did not affect the accuracy of the part.

\subsubsection{Program Preparation Time}

The preparation times of the machining programs for all three cases are presented in Table 2. The automatic programming according to ACPUT requires developing the template (Step 4 in Fig. 2); therefore, the preparation time for the first part was much longer in this case than the preparation times for the subsequent parts. A difference can also be seen in the case of the programmers (both expert and beginner), programming in the traditional manner, but it not as striking as in the ACPUT case. The differences between the programming time of an expert and beginner programmers are related to their different proficiency in using the CAM program.

The total time of the beginner programmers amounts to $2018 \mathrm{~min}$ ( $226 \%$ of the ACPUT time), while the experts had a working time of $1175 \mathrm{~min}$ (132\% of ACPUT). The results presented in Table 2 are also shown in Fig. 6. This shows that the ACPUT procedure is already justified when the group of parts is greater than four.

Table 2. Comparison of preparation time for machining programs

\begin{tabular}{|c|c|c|c|c|c|c|c|c|}
\hline \multicolumn{9}{|c|}{ CAM preparation time [min] } \\
\hline \multirow[t]{2}{*}{ Part No. } & \multicolumn{2}{|c|}{ ACPUT procedure } & \multicolumn{3}{|c|}{$\begin{array}{l}\text { Standard procedure - Beginners } \\
\text { (average for } 5 \text { participants) }\end{array}$} & \multicolumn{3}{|c|}{$\begin{array}{l}\text { Standard procedure - Experts } \\
\text { (average for } 5 \text { participants) }\end{array}$} \\
\hline & $\mathrm{Ti}$ & rising & $\mathrm{Ti}$ & rising & Range & $\mathrm{Ti}$ & rising & Range \\
\hline 1 & 224 & 224 & 145 & 145 & 43 & 79 & 79 & 17 \\
\hline 2 & 12 & 236 & 58 & 203 & 7 & 28 & 107 & 11 \\
\hline 3 & 14 & 250 & 42 & 245 & 10 & 29 & 136 & 6 \\
\hline 4 & 11 & 261 & 42 & 287 & 21 & 18 & 154 & 8 \\
\hline 5 & 13 & 274 & 41 & 328 & 15 & 32 & 186 & 7 \\
\hline 6 & 11 & 285 & 35 & 363 & 8 & 25 & 211 & 3 \\
\hline 7 & 12 & 297 & 39 & 402 & 18 & 28 & 240 & 13 \\
\hline 8 & 10 & 307 & 44 & 445 & 9 & 20 & 260 & 8 \\
\hline 9 & 13 & 320 & 40 & 485 & 14 & 27 & 287 & 11 \\
\hline 10 & 10 & 330 & 37 & 522 & 19 & 22 & 309 & 6 \\
\hline$\ldots$ & $\ldots$ & $\ldots$ & $\ldots$ & $\ldots$ & $\ldots$ & $\ldots$ & $\ldots$ & \\
\hline 20 & 11 & 460 & 38 & 914 & 7 & 18 & 519 & 3 \\
\hline 30 & 14 & 606 & 29 & 1286 & 9 & 16 & 727 & 11 \\
\hline 40 & 19 & 752 & 41 & 1673 & 15 & 26 & 955 & 19 \\
\hline 50 & 10 & 891 & 30 & 2018 & 14 & 18 & 1175 & 7 \\
\hline
\end{tabular}




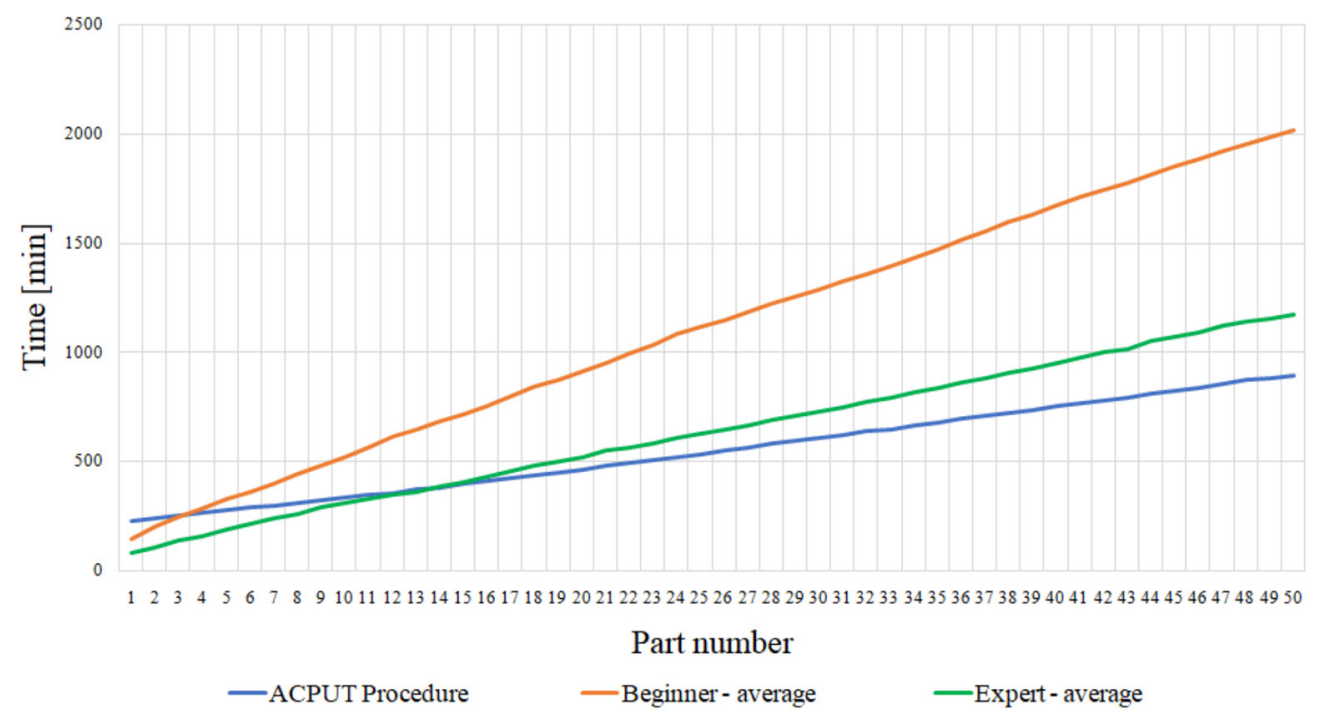

Fig. 6. CAM preparation time -rising

A summary of the machining times from the simulation for each part separately and rising are presented in Table 3 and Fig. 7. Because the parameters and the method of processing were specified in the technological knowledge base, and each of the programmers operated using the same data, the differences in the machining times for individual parts were insignificant. The difference between the ACPUT procedure and the expert programmers was $3.3 \%$, while between the ACPUT procedure and the beginner programmers amounted to $5.3 \%$. This mainly resulted from the selection of other speeds and the tool's path of movement during its approach and departure from the workpiece. It should be emphasized here that these parameters were not specified in the technological knowledge base.

The total time for the preparation of the machining programs and the machining for all 50 parts was $4863 \mathrm{~min}$ in the case of the programming using ACPUT procedure, $6200 \mathrm{~min}$ (representing $127.5 \%$

Table 3. Part machining time on CNC machine based on simulation in CAM program

\begin{tabular}{|c|c|c|c|c|c|c|}
\hline \multicolumn{7}{|c|}{ Machining time [min] } \\
\hline \multirow[t]{2}{*}{ Part No. } & \multicolumn{2}{|c|}{ ACPUT procedure } & \multicolumn{2}{|c|}{$\begin{array}{l}\text { Standard procedure - Beginner } \\
\text { (average for } 5 \text { participants) }\end{array}$} & \multicolumn{2}{|c|}{$\begin{array}{l}\text { Standard procedure - Expert } \\
\text { (average for } 5 \text { participants) }\end{array}$} \\
\hline & for each & Tc & for each & Tc & for each & $\mathrm{Tc}$ \\
\hline 1 & 141 & 141 & 147 & 147 & 126 & 126 \\
\hline 2 & 87 & 228 & 86 & 233 & 94 & 220 \\
\hline 3 & 119 & 347 & 127 & 360 & 123 & 343 \\
\hline 4 & 43 & 390 & 47 & 407 & 44 & 387 \\
\hline 5 & 77 & 467 & 80 & 486 & 78 & 465 \\
\hline 6 & 42 & 509 & 46 & 533 & 44 & 509 \\
\hline 7 & 86 & 595 & 90 & 622 & 85 & 594 \\
\hline 8 & 43 & 638 & 47 & 669 & 45 & 639 \\
\hline 9 & 99 & 737 & 106 & 775 & 98 & 737 \\
\hline 10 & 45 & 782 & 49 & 824 & 44 & 780 \\
\hline$\ldots$ & $\ldots$ & $\ldots$ & $\ldots$ & $\ldots$ & $\ldots$ & $\ldots$ \\
\hline 20 & 82 & 1800 & 85 & 1885 & 83 & 1826 \\
\hline 30 & 51 & 2610 & 55 & 2740 & 51 & 2673 \\
\hline 40 & 59 & 3292 & 58 & 3471 & 66 & 3408 \\
\hline 50 & 49 & 3972 & 52 & 4182 & 49 & 4102 \\
\hline
\end{tabular}




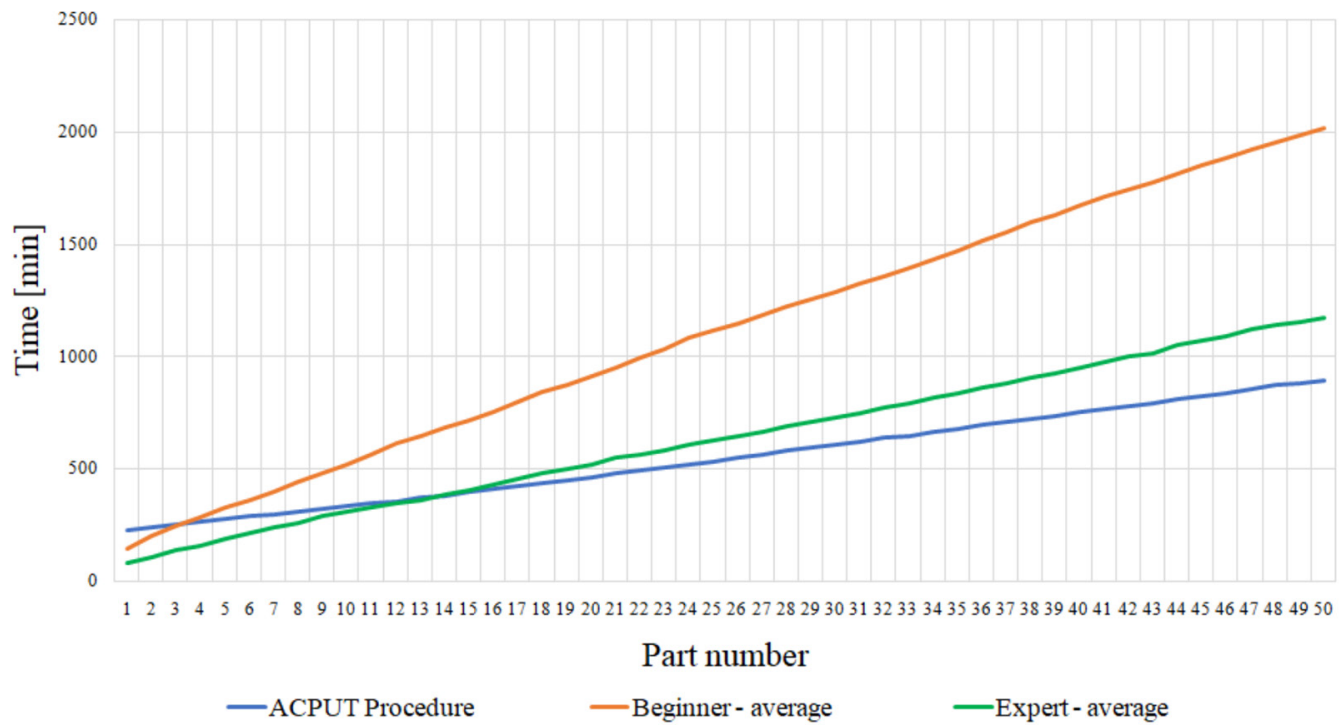

Fig. 7. Machining time - rising

of the working time of the ACPUT procedure) for the beginner technicians and $5277 \mathrm{~min}(108.5 \%$ of the working time of the automatic solution) for the expert technicians. The above data are presented in Table 4.

\subsubsection{Manufacturing Costs}

The average cost for the machine programming for a single part $(M P c)$ for a given number of parts in the group $(G s)$, where $(P r)$ is a pay rate for the CAM programmer/technician is:

$$
M P c=\left(\Sigma T_{i} / 60 \times P r\right) / G s .
$$

Supposing the pay rate for the beginner programmer $(P r b)$ was $€ 60 / \mathrm{h}$ and the expert's pay rate (Pre) was $€ 80 / \mathrm{h}$, it emerged that the average cost for the machine programming for a single part $(M P c)$ from a given group of parts $(G s)$, was respectively, $€$ 40 for the beginner and $€ 31$ for the expert.

In the case of the ACPUT procedure, to build a machining template, expert knowledge is necessary, while to program the machining of subsequent parts,

Table 4. Total manufacturing time

\begin{tabular}{|c|c|c|c|c|c|c|}
\hline \multicolumn{7}{|c|}{ CAM preparation and machining time [min] } \\
\hline \multirow[t]{2}{*}{ Part No. } & \multicolumn{2}{|c|}{ ACPUT procedure } & \multicolumn{2}{|c|}{$\begin{array}{l}\text { Standard procedure - Beginner } \\
\text { (average for } 5 \text { participants) }\end{array}$} & \multicolumn{2}{|c|}{$\begin{array}{l}\text { Standard procedure - Expert } \\
\text { (average for } 5 \text { participants) }\end{array}$} \\
\hline & for each & Tc & for each & $\mathrm{Tc}$ & for each & $\mathrm{TC}$ \\
\hline 1 & 365 & 365 & 292 & 292 & 205 & 205 \\
\hline 2 & 99 & 464 & 144 & 436 & 123 & 328 \\
\hline 3 & 133 & 597 & 169 & 605 & 151 & 479 \\
\hline 4 & 54 & 651 & 89 & 694 & 62 & 541 \\
\hline 5 & 90 & 741 & 121 & 815 & 109 & 651 \\
\hline 6 & 53 & 794 & 81 & 896 & 69 & 720 \\
\hline 7 & 98 & 892 & 128 & 1024 & 113 & 833 \\
\hline 8 & 53 & 945 & 90 & 1114 & 66 & 899 \\
\hline 9 & 112 & 1057 & 146 & 1260 & 125 & 1024 \\
\hline 10 & 55 & 1112 & 86 & 1347 & 65 & 1089 \\
\hline$\ldots$ & $\ldots$ & $\ldots$ & $\ldots$ & $\ldots$ & $\ldots$ & $\ldots$ \\
\hline 20 & 93 & 2260 & 122 & 2798 & 101 & 2344 \\
\hline 30 & 65 & 3216 & 83 & 4026 & 67 & 3400 \\
\hline 40 & 78 & 4044 & 99 & 5145 & 92 & 4363 \\
\hline 50 & 59 & 4863 & 82 & 6200 & 67 & 5277 \\
\hline
\end{tabular}


the knowledge of a beginner programmer is sufficient. Thus:

$$
M P c=\left[T_{1} / 60 \times \operatorname{Pre}+\left(\Sigma\left(T_{i}-T_{1}\right)\right) / 60 \times \operatorname{Pr} b\right] / G s .
$$

In the case above, the first part of the procedure assumed a man-hour cost of $€ 80 / \mathrm{h}$ while for the next it totalled $€ 60 / \mathrm{h}$. It follows that for the ACPUT procedure, the average programming cost for machining a single part was $€ 19$.

Assuming a pay rate of $€ 35 / \mathrm{h}$, the average cost of the machining for a single part in ACPUT procedure was $€ 46$, by beginner programmer (average) $€ 49$ and for the expert programmer $€ 48$.

The individual cost of tool manufacture $C_{m}$ [EUR], consisting of the cost of preparing the machining programs $(M P c)$ and the cost of machining itself, was the lowest for the ACPUT procedure - an average of $€ 66$ per part ( $€ 3300$ for all 50 parts). In the case of the beginner technicians, the $C_{m}$ was $€ 89$ (135.8\% of ACPUT $C_{m}, € 4450$ for all 50 parts) and $€ 79\left(120.6 \% 35.8 \%\right.$ of ACPUT $C_{m}, € 3950$ for all 50 parts) for the experts. A summary of $C_{m}$ is presented in Fig. 8.

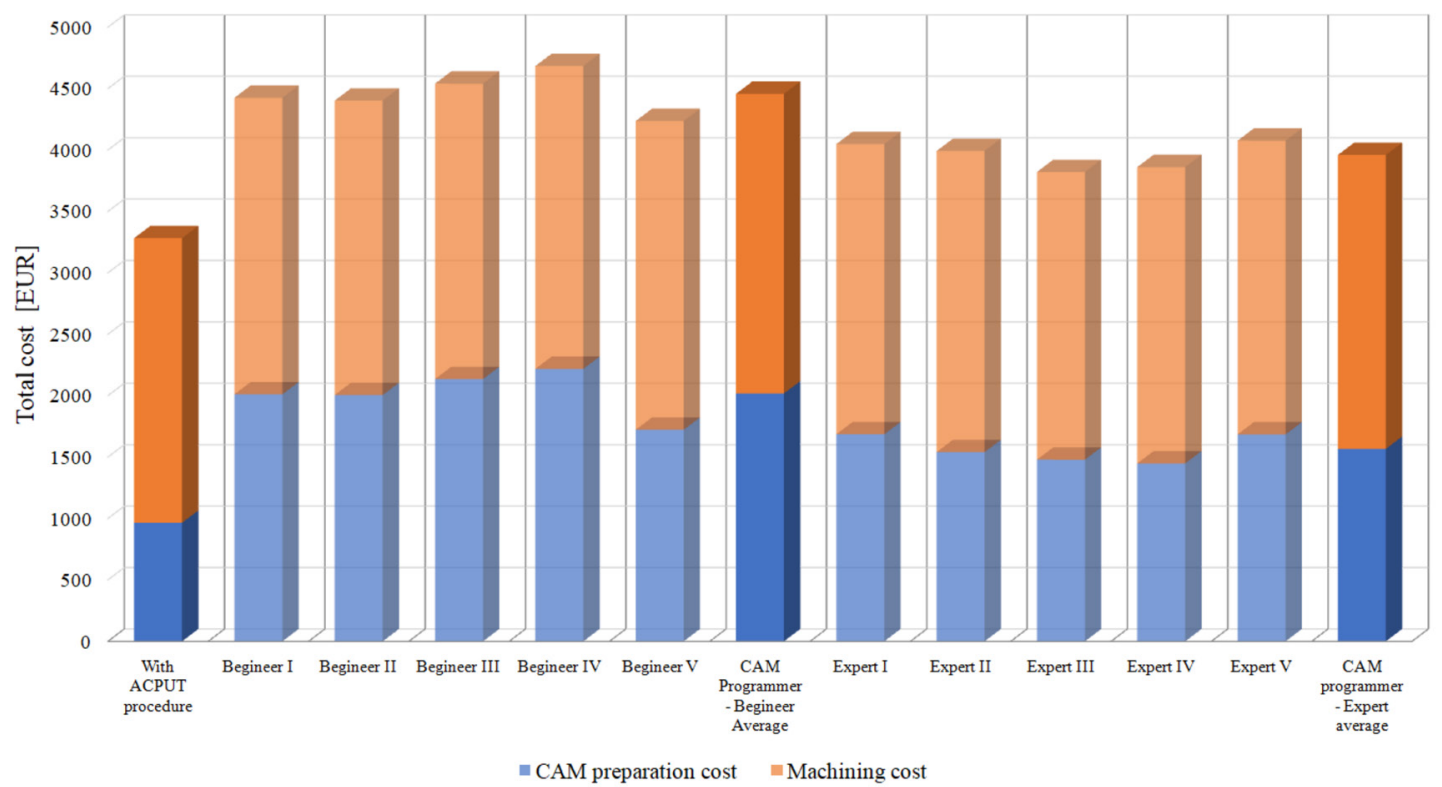

Fig. 8. Special production tooling manufacture costs

\section{SUMMARY AND CONCLUSIONS}

In the present paper, a CAM programming procedure, called ACPUT, was presented. ACPUT is dedicated to the manufacture of special technological tooling, which consists of technologically similar parts. The procedure includes the development of special machining templates in the CAM program, supported by the technological knowledge gathered in a specially prepared database.

The theoretical functionality of ACPUT was studied in earlier work, but it was necessary to validate its practical effectiveness, taking time and cost of manufacturing the group of tooling into account. Therefore, the main aim of this research was to check when the automatic CAM programming method would be better than the traditional CAM programming approach.
Testing under industrial conditions showed that the ACPUT procedure makes it possible to reduce the time needed to develop a machining program. This has a positive effect on the total cost of tooling production.

The effectiveness of ACPUT was tested based on the analysis of the time needed to prepare the $\mathrm{CNC}$ program and the machining operation time itself (based on the simulation in CAM). The preparation time of the program is a direct (next to the quality conditions) indicator of the effectiveness of ACPUT. Analysing Table 2 and Fig. 6, it can be seen that the time benefits of using an automatic solution are significant, especially when compared to a less experienced technician.

It should be emphasized that the effectiveness of the ACPUT procedure depends on the experience of those who prepare the templates. For the tests 
carried out, ten CAM programmers were invited to participate: five with several years' experience and five with limited experience (working in this position for only a few months). The first group was considered an expert and the second asa beginner. The aim of the study was not to indicate the predictable differences between them but to evaluate ACPUT which constituted a reference. Separating the technicians into more experienced and less experienced groups had one more purpose: to assess whether, after preparing the machining templates according to ACPUT, someone with less experience would be able to use the automatic solution successfully. The study revealed that it was possible: the results obtained using the automatic solution was even better than the work produced by expert.

The ACPUT procedure is, in its assumption, universal; it does not require the use of any specific CAM system or knowledge base construction program, because it does not indicate the use of specific tools to prepare the machining templates. In this study, the CATIA V5 program was used to build the machining template, but it should be considered an example of the possible software that can be used. Machining templates can also be built in other systems of this type. However, it is worth emphasizing that it is best to use integrated CAD/CAM software for these purposes (thereby facilitating data exchange).

However, attention should be paid to certain limitations related to the practical application of the proposed method. Firstly, the automation of $\mathrm{CNC}$ machine programming according to the ACPUT method assumes the preparation of machining templates for a given family of parts. Their development is, of course, possible in advanced $\mathrm{CAD} / \mathrm{CAM}$ programs. However, it requires skills in the field of VB programming in order to develop algorithms that allow for automatic recognition of specific geometric features of the machined part and appropriate technological operations in CAM to be assigned to them. In addition, the implementation of programming automation according to ACPUT requires the development and description of standards for the technology used within production companies. For the correct, automatic generation of machining programs in the future, it is advisable to create a knowledge base dependent on the experience of the employees and the analysis of archival works.

The achieved results are satisfying, and the conclusions seem useful for practical use. The automation of CAM programming is laborious, complicated and, therefore, difficult to implement in practice. In many cases, the automation of CAM programming does not achieve the assumed results (e.g., the program preparation time gain is not significant) because it is difficult to evaluate the labour intensity for the whole group of manufacturing tools. Research of the ACPUT method complements the knowledge in this field.

In terms of further research, it would be worth checkingthe possibility of generating programs for specific types of CNC machine controls. However, in the meantime, more immediate research will focus on the development of a method for the rapid assessment of the technological similarity of the parts for which the preparation of a machining template is planned. It is expected that if the difference between the parts is too great, it will not be profitable to prepare the template and apply the ACPUT procedure. In such a case, it would be preferable to use the traditional programming procedure.

\section{ACKNOWLEDGEMENTS}

We thank the all technology team from Mk-Tech Company for providing a special tooling project for our research, for sharing knowledge about holding milling processes and for helping us during the tests. We also thank Radoslaw Paszkiewicz from Poznan University of Technology for valuable tips and tricks used in CAM programming in the Catia system.

The presented results were financed from statutory scientific research conducted by the Faculty of Mechanical Engineering, Poznan University of Technology, Poland, supported by the Polish Ministry of Science and Higher Education from the financial means in 2021, no.0613/SBAD/4677.

\section{REFERENCES}

[1] Lu, Y. (2017). Industry 4.0: A survey on technologies, applications and open research issues. Journal of Industrial Information Integration, vol. 6, p. 1-10, D0l:10.1016/j. jii.2017.04.005.

[2] Alcacer, V., Cruz-Machado, V. (2019). Scanning the Industry 4.0: A Literature Review on Technologies for Manufacturing Systems. Engineering Science and Technology, an International Journal, vol. 22, no. 3, p. 899-919, D0I:10.1016/j.jestch.2019.01.006.

[3] Brettel, M., Friederichsen, N., Keller, M., Rosenberg, M.(2014). How virtualization, decentralization and network building change the manufacturing landscape: An Industry 4.0 perspective. International Journal of Mechanical, Aerospace, Industrial, Mechatronic and Manufacturing Engineering, vol. 8, no. 1, Dol:10.5281/zenodo.1336426.

[4] Hamrol, A., Gawlik, J., Sładek, J. (2019). Mechanical engineering in Industry 4.0. Management and Production 
Engineering Review, vol. 10, no. 3, p. 14-28, Dol:10.24425/ mper.2019.129595.

[5] Gök, A., Gök, K., Bilgin, M.B., Alkan, M.A. (2017). Effects of cuttingparameters and tool-pathstrategies on toolacceleration in ball-end milling. Materials and Technology, vol. 51, no. 6, p. 957-965, D0I:10.17222/mit.2017.039.

[6] Gok, A. (2015). A newapproachtominimization of thesurfaceroughness and cuttingforce via fuzzy TOPSIS, multiobjectivegrey design and RSA. Measurement, vol. 70, p. 100109, D0I:10.1016/j.measurement.2015.03.037.

[7] Liu, Y., Xu, X. (2017). Industry 4.0 and cloud manufacturing: A comparative analysis. Journal of Manufacturing Science and Engineering, vol. 139, no. 3, art ID: 034701, DOl:10.1115/1.4034667.

[8] Fogliatto, F.S., Da Silveira, G.J.C., Borenstein, D. (2012). The mass customization decade: An updated review of the literature. International Journal of Production Economics, vol. 138, no. 1, p. 14-25, D0l:10.1016/j.ijpe.2012.03.002.

[9] Zawadzki, P., Żywicki, K. (2016). Smart product design and production control for effective mass customization in the Industry 4.0 concept. Management and Production Engineering Review, vol. 7, no. 3, p. 105-112, Dol:10.1515/ mper-2016-0030.

[10] Zawadzki, P. (2018). Methodology of KBE system development for automated design of multivariant products. In: Hamrol, A., Ciszak, 0., Legutko, S., Jurczyk, M. (eds). Advances in Manufacturing, Lecture Notes in Mechanical Engineering, p. 239-248, Springer, Cham, Dol:10.1007/978-3-319-686196 23.

[11] Kowalski, M., Zawadzki, P. (2019). Tooling CAD models preparation process for automated technology design system. In: Hamrol, A., Kujawińska, A., Barraza, M. (eds.). Advances in Manufacturing II. MANUFACTURING. Lecture Notes in Mechanical Engineering, Springer, Cham, Dol:10.1007/978-3030-18789-7_4.

[12] Kowalski, M., Zawadzki, P. (2019). Decomposition of knowledge for automatic programming of CNC machines. Management and Production Engineering Review, vol. 10, no. 1, Dol:10.24425/mper.2019.128248.

[13] Strandhagen, J.W., Vallandingham, L.R., Alfnes, E., Strandhagen, J.O. (2018). Operationalizing lean principles for lead time reduction in engineer-to-order (ETO) operations: A case study. IFAC-PapersOnLine, vol. 51, no. 11, p. 128-133, DOI:10.1016/j.ifacol.2018.08.246.

[14] Kowalski, M. (2020). Method of automatic CAM programming using machining templates. Mechanik, vol. 93, no. 1, p. 4852, D0I:10.17814/mechanik.2020.1.4.

[15] Verma, A.K., Rajotia, S. (2010). A review of machining feature recognition methodologies. International Journal of Computer Integrated Manufacturing, vol. 23, no. 4, p. 353-368, DOI:10.1080/09511921003642121.

[16] Chevalier, P.W. (1984). Group technology as a CAD/CAM integrator in batch manufacturing. International Journal of Operations \& Production Management, vol. 4, no. 3, p. 3-12, DOl:10.1108/eb054715.

[17] Babic, B., Nesic, N., Miljkovic, Z. (2008). A review of automated feature recognition with rule-based pattern recognition. Computers in Industry, vol. 59, no. 4, p. 321-337, DOI:10.1016/J.compind.2007.09.001.

[18] Zhang, Z., Jaiswal, P., Rai, R. (2018). Featurenet: Machining feature recognition based on $3 \mathrm{D}$ convolution neural network. Computer-Aided Design, vol. 101, p. 12-22, D0I:10.1016/j. cad.2018.03.006.

[19] Sateesh, P., Mahesh, P.V. (2017). A methodology for feature extraction and recognition for CAD/CAM integration using step file. International Journal of Research and Innovation, vol. 4, no. 1, p. 711-725.

[20] Skvortsov, V., Proletarsky, A., Arzybaev, A. (2019). Feature recognition module of the CAPP system. IEEE Conference of Russian Young Researchers in Electrical and Electronic Engineering, p. 1769-1772, D0l:10.1109/ ElConRus.2019.8656655.

[21] Zhou, G., Yang, X., Zhang, C., Li, Z., Xiao, Z. (2019). Deep learning enabled cutting tool selection for special-shaped machining features of complex products. Advances in Engineering Software, vol. 133, p. 1-11, D0l:10.1016/j. advengsoft.2019.04.007.

[22] Andriankaja, H., Le Duigou, J., Eynard, B. (2015). Sustainable machining approach by integrating the environmental assessment within the CAD/CAM/CNC Chain. In Chakrabarti, A. (ed). ICORD'15-Research into Design Across Boundaries Volume 2. Smart Innovation, Systems and Technologies, p. 227-236. Springer, New Delhi, Dol:10.1007/978-81-3222229-3_20.

[23] Zhou, H., Wu, J. (2016). Research on CAD/CAM Integration Methods Based on the STL Model. In Proceedings of the 5th International Conference on Electrical Engineering and Automatic Control, Lecture Notes in Electrical Engineering, vol. 367. p. 1201-1207, Springer, Berlin, Heidelberg, DOI:10.1007/978-3-662-48768-6_134.

[24] De Lacalle, L.L., Lamikiz, A., Muñoa, J., Salgado, M.A., Sánchez, J.A. (2006). Improving the high-speed finishing of forming tools for advanced high-strength steels (AHSS). The International Journal of Advanced Manufacturing Technology, vol. 29, p. 49-63, D0l:10.1007/s00170-004-2482-z.

[25] De Lacalle, L.L., Lamikiz, A., Salgado, M.A., Herranz, S., Rivero, A. (2002). Process planning for reliable high-speed machining of moulds. International Journal of Production Research, vol. 40, no. 12, p. 2789-2809, D0l:10.1080/00207540210140068.

[26] Zahid, M.N.O., Case, K., Watts, D. (2017). Rapid process planning in CNC machining for rapid manufacturing applications. International Journal of Mechanical Engineering and Robotics Research, vol. 6, no. 2, p. 118-121, DOI:10.18178/ijmerr.6.2.118-121.

[27] Deja, M., Siemiatkowski, M.S. (2013). Feature-based generation of machining process plans for optimised parts manufacture. Journal of Intelligent Manufacturing, vol. 24, p. 831-846, D0l:10.1007/s10845-012-0633-x.

[28] Tan, C.F., Kher, V.K., Ismail, N. (2013). Design of a feature recognition system for CAD/CAM integration. World Applied Sciences Journal, vol. 21, no. 8, p. 1162-1166, D0l:10.5829/ idosi.wasj.2013.21.8.2126.

[29] Sivakumar, S., Dhanalakshmi, V. (2013). An approach towards the integration of $C A D / C A M / C A l$ through STEP file using feature extraction for cylindrical parts. International Journal 
of Computer Integrated Manufacturing, vol. 26, no. 6, p. 561570, DOI:10.1080/0951192X.2012.749527.

[30] Miao, H.K., Sridharan, N., Shah, J.J. (2002). CAD-CAM integration using machining features. International Journal of Computer Integrated Manufacturing, vol. 15, no. 4, p. 296318, DOI:10.1080/09511920110077502.

[31] Sivakumar, S., Dhanalakshmi, V. (2013). A feature-based system for CAD/CAM integrationthrough STEP file for cylindrical parts. Indian Journal of Engineering \& Material Sciences, vol. 20, p. 21-26, D0l:10.1080/0951192X.2012.749527.

[32] Xu, T., Chen, Z., Li, J., Yan, X. (2015). Automatic tool path generation from structuralized machining process integrated with CAD/CAPP/CAM system. The International Journal of Advanced Manufacturing Technology, vol. 80, p. 1097-1111, DOI:10.1007/s00170-015-7067-5.

[33] Wang, J., Zhang, H.L., Su, Z.Y. (2012). Manufacturing knowledge modeling based on artificial neural network for intelligent CAPP. Applied Mechanics and Materials, vol. 127, p. 310-315, D0I:10.4028/www.scientific.net/AMM.127.310.

[34] Li, J., Chen, Z.,Yan, X. (2014). Automatic generation of inprocess models based on feature working step and feature cutter volume. The International Journal of Advanced Manufacturing Technology, vol. 71, no. 1-4, p. 395-409, DOl:10.1007/s00170-013-5507-7.

[35] Ma, H., Zhou, X., Liu, W., Li, J., Niu, Q., Kong, C. (2018). A feature-based approach towards integration and automation of CAD/CAPP/CAM for EDM electrodes. The International Journal of Advanced Manufacturing Technology, vol. 98,p. 2943-2965, D0I:10.1007/s00170-018-2447-2.

[36] Kumar, S.P.L. (2017). State of the art-intense review on artificial intelligence systems application in process planning and manufacturing. Engineering Applications of Artificial Intelligence, vol. 65, p. 294-329, D0l:10.1016/j. engappai.2017.08.005.
[37] Li, S., Li, J., Ma, Y., Liu, G. (2018). Application of Intelligent process decision in CAPP. International Arab Journal of e-Technology, vol. 5, no. 2, p. 71-77.

[38] Leo Kumar, S.P. (2018). Automation of tool path generation in multi-process micromachine tool for micromachining of prismatic and rotational parts. International Journal of Computer Integrated Manufacturing, vol. 31, no. 1, p. 49-70, DOI:10.1080/0951192X.2017.1356471.

[39] Li, X., Zhang, S., Huang, R., Huang, B., Xu, C., Zhang, Y. (2018). A survey of knowledge representation methods and applications in machining process planning. The International Journal of Advanced Manufacturing Technology, vol. 98, p. 3041-3059, D0l:10.1007/s00170-018-2433-8.

[40] Ma, H., Zhou, X., Liu, W., Li, J., Niu, Q., Kong, C. (2018). A feature-based approach towards integration and automation of CAD/CAPP/CAM for EDM electrodes. The International Journal of Advanced Manufacturing Technology, vol. 98, p. 2943-2965, D0l:10.1007/s00170-018-2447-2.

[41] Venu, B., Komma, V.R., Srivastava, D. (2018). STEP-based feature recognition system for B-spline surface features. International Journal of Automation and Computing, vol. 15, p. 500-512, D0I:10.1007/s11633-018-1116-0.

[42] Lavrentyeva, M.V., Chimitov, P.Y. (2017). Implementation of recognition algorithm with NXOpen API in siemens NX. International Conference on Industrial Engineering, Applications and Manufacturing, p. 1-4, D0l:10.1109/ ICIEAM.2017.8076193.

[43] Klancnik, S., Brezocnik, M., Balic, J. (2016). Intelligent CAD/CAM system for programming of CNC machine tools. International Journal of Simulation Modelling, vol. 15, no. 1, p. 109-120, D0I:10.2507/IJSIMM15(1)9.330.

[44] Chung, C., Ma, T. (2017). Implementation of CAM programming with machinability database. IEEE/SICE International Symposium on System Integration, p. 236-240, D0I:10.1109/ SII.2017.8279218. 